\title{
Crustal contamination in the generation of Liuyuan basalts: Implication for Permian evolution of the southern Central Asian Orogenic Belt
}

\author{
YUANYANG YU AND KEQING ZONG
}

China University of Geosciences(Wuhan)

Presenting Author: cug.yyyu@gmail.com

Liuyuan basaltic belt located in the southern Beishan Orogenic Belt plays an important role to constrain the evolution of the southern Central Asian Orogenic Belt (CAOB). However, the genesis of the Liuyuan basaltic belt is ambiguous. Here bulk rock elements and $\mathrm{Sr}-\mathrm{Nd}-\mathrm{Pb}-\mathrm{Hf}$ isotopes and zircon $\mathrm{U}-\mathrm{Pb}$ ages and $\mathrm{Lu}-\mathrm{Hf}$ isotopes were analyzed for the Liuyuan basalts and within gabbros, respectively. Two gabbro samples from the central Liuyuan basaltic belt yielded zircon ${ }^{206} \mathrm{~Pb} /{ }^{238} \mathrm{U}$ ages of $288 \pm 1 \mathrm{Ma}$ and $294 \pm 1 \mathrm{Ma}$, respectively, which represents the formation time of the Liuyuan basaltic belt in the early Permian. Liuyuan basalts show MORB-like rare earth element (REE) patterns and $\varepsilon_{\mathrm{Hf}(\mathrm{t})}$ values are as high as 15.4, which suggest Liuyuan basalts derived from a depleted mantle source. However, the presence of positive $\mathrm{Pb}$ anomalies, $\mathrm{Nb}-\mathrm{Ta}$ depletions and high $\mathrm{Th} / \mathrm{Yb}$ ratios and evolved Sr-Nd-Pb-Hf isotopic compositions $\left(\left({ }^{87} \mathrm{Sr} /{ }^{86} \mathrm{Sr}\right)_{\mathrm{i}}=0.703\right.$ $0.705, \varepsilon_{\mathrm{Nd}(\mathrm{t})}=4.6-9.2,\left({ }^{206} \mathrm{~Pb} /{ }^{204} \mathrm{~Pb}\right)_{\mathrm{i}}=17.80-18.36, \varepsilon_{\mathrm{Hf}(\mathrm{t})}=+11.0$ to +15.4 ) indicate the contribution of continental crustal materials in the generation of Liuyuan basalts. Combing with covariation of $\mathrm{Pb}$ anomalies $\left(\mathrm{Pb}^{*}=0.36-1.41\right)$ with $\mathrm{Sr}-\mathrm{Nd}-\mathrm{Pb}-\mathrm{Hf}$ isotopic compositions, we conclude that Liuyuan basalts have been contaminated by a low proportion $(<10 \%)$ of continental crustal materials rather than enriched mantle source, which is consistent with one gabbro sample shows obviously low bulk rock $\varepsilon_{\mathrm{Hf}(\mathrm{t})}$ than within zircons (13 versus 14-17).Therefore, Liuyuan basaltic belt should be formed in a continental extension environment instead of an oceanic setting, which thus can not be considered as a Permian ophiolitic suture as previous suggestion to represent the early Permian closure of the Paleo-Asian Ocean in the southern CAOB. 